\title{
Electrochemical Studies of Immobilized Laccases on the Modified-Gold Electrodes
}

\author{
Chang-Jung Yoon and Hyug-Han Kim ${ }^{\dagger *}$ \\ *Department of Chemistry, Dankook University, Cheonan 330-714, Korea \\ (Received December 3, 2003 : Accepted February 10, 2004)
}

\begin{abstract}
The direct electrochemical studies of four laccases (plant and fungal laccases) have been investigated on a gold electrode functionalized with a new tether of $2.2^{\prime}$-dithiosalicylic aldehyde. Results from these studies indicate that the redox potential of the active site of plant laccase from Rhus vernificera is shifted to a more negative value ( $255 \mathrm{mV}$ versus SCE) than that of fungal laccase from Pyricularia oryzae ( $480 \mathrm{mV}$ versus SCE). Mechanistic studies indicate that the reduction of type-1 $\mathrm{Cu}$ precedes the reduction of type- 2 and type- $3 \mathrm{Cu}$ ions when the electrode is poised initially at different potentials. Also a new tether, 2.2'-dithiosalicylic aldehyde, has been used to study the redox properties of two laccases (LCCI and LCCIa) covalently attached to a gold electrode. An irreversible peak at $0.47 \mathrm{~V}$ vs. SCE is observed in the cyclic voltammograms of LCCI. In contrast, the cyclic voltammograms of LCCIa contain a quasi-reversible peak at $0.18 \mathrm{~V}$ vs. SCE and an irreversible peak at $0.50 \mathrm{~V}$ vs. SCE. We find that the replacement of the eleven amino acids a the C-terminus with a single cysteine residue (i.e., LCCI $\rightarrow$ LCCla) influences the rate of heterogeneous electron transfer between an electrode and the copper containing active sites $\left(\mathrm{K}_{\mathrm{het}}\right.$ for $\mathrm{LCCI}=1.0$ $\times 10^{-2} \mathrm{~s}^{-1}$ and $\mathrm{K}_{\text {het }}$ for LCCIa $=1.0 \times 10^{-1} \mathrm{~s}^{-1}$ at $0.18 \mathrm{~V}$ versus SCE and $4.0 \times 10^{-2} \mathrm{~s}^{-1}$ at $0.50 \mathrm{~V}$ versus SCE). These results show for the first time that the change of the primary structure of a protein via site-directed mutagenesis influences both the redox potentials of the copper ions in the active site and the rate of heterogeneous electron transfer
\end{abstract}

Key words : Laccase, Cyclic voltammetry, Mutagenesis, Heterogeneous electron transfer

\section{Introduction}

The direct electrochemical studies of laccases (oxygen oxidoreductase; EC 1.10.3.2) have been investigated at aldehyde-terminated ${ }^{1-3)}$ thiol monolayers on gold. ${ }^{4-11)}$ Laccase is a multi-copper containing oxidase that couples four one-electron oxidations of organic and inorganic substrates to one four-electron reduction of dioxygen to water. ${ }^{12-23)}$ The active site of laccase contains four copper ions [Cu(II/I), classified according to their EPR characteristics] with coordination sphere of the histidine and cysteine residues. ${ }^{24-26)}$ Despite many structural and kinetic studies, blue copper protein ${ }^{21,27)}$ have not been studied electrochemically ${ }^{28)}$ in the presence of chemical promotors or redox mediators. ${ }^{29-33)}$

Gold electrodes modified with an aldehyde-terminated thiol monolayer chemically react with amine-containing molecules in the absence of other reagents. The aldehyde-terminated monolayers immobilize enzymes onto gold electrodes and facilitate heterogeneous electron transfer between the active site of the bound oxidoreductase and the electrode surface.

In this paper, we describe the electrochemistry of plant and fungal laccases in the absence of redox mediators. Results from these studies indicate that laccases originating from plant and fungal sources have different redox potentials. These results demonstrate the difference in redox potential of plant laccase from Rhus vernificera and fungal laccase from Pyricularia oryzae. In addition, we include results from electrochemical studies of immobilized LCCI and LCCIa (fungal laccases from Trametes versicolor expressed by heterologous host, Pichia pastoris), and compare these results to those obtained from solution studies of LCCI and LCCIa. Results from these studies show that a deletion at the C-terminus of wild-type fungal laccase (LCCI to LCCIa) influences both the redox potential of laccase and increases the rate of heterogeneous electron transfer. These results agree well with our previous studies on solutions containing LCCI and LCCla.

\section{Experimental}

\subsection{Chemicals}

Fungal laccase (benzenediol:oxygen oxidoreductase; EC 1.10.3.2) from Pyricularia oryzae $\left(6,940\right.$ units $\mathrm{mg}^{-1}$ protein using syringaldazine as substrate) and plant laccase (benzenediol: oxygen oxidoreductase; EC 1.10.3.2) from Rhus vernificera (50 units $\mathrm{mg}^{-1}$ protein using syringaldazine as substrate) were purchased from Sigma. 2,2'-Azinobis (3-ethylbenzothiazoline-6-sulfonate) diammonium salt (ABTS) and chemicals used to prepare buffered solutions were purchased from Aldrich and were used as received. Water in electrolyte solutions was ultrapure $(18.2 \mathrm{M} \Omega)$.

${ }^{\dagger}$ E-mail: hankim@dankook.ac.kr 


\subsection{Synthesis of 2.2 '-dithiosalicylic aldehyde}

2.2'-dithiosalicylic aldehyde was synthesized using the following procedure: thiolphenol $(2.5 \mathrm{~g}, 22.7 \mathrm{mmol})$ dissolved in anhydrous cyclohexane $(60 \mathrm{~mL})$ under argon at $-78^{\circ} \mathrm{C}$ was added to distilled $\mathrm{N}, \mathrm{N}, \mathrm{N}^{\prime}, \mathrm{N}^{\prime}$-tetramethylethylenediamine (TMEDA, $7.53 \mathrm{~mL}, 50 \mathrm{mmol}$ ) and subsequently added to $\mathrm{n}$ butyllithium $(31.75 \mathrm{~mL}$ of a $1.6 \mathrm{M}$ solution in hexane, 50 mmol). The resulting solid was allowed to dry at room temperature to give a pale yellow solution, which gave a white suspension when stirred overnight. Lithium 2-lithiobenzenethiolate in ice-bath was added dimethylformamide (DMF, $4.27 \mathrm{~mL}, 55 \mathrm{mmol})$ in nonaqueous cyclohexane $(20 \mathrm{~mL})$. The mixture was allowed to dry at room temperature to give a pale yellow suspension, and then poured into $10 \%$ aqueous hydrochloric acid $(\mathrm{HCl}, 50 \mathrm{~mL})$ to give a clear pale yellow solution. Mixture of aldehyde solution in tetrahydrofuran $(30 \mathrm{~mL})$ at room temperature was added $10 \%$ aqueous $\mathrm{HCl}$ $(15 \mathrm{~mL})$. The mixture was stirred at room temperature for 2 days, and then extracted with diethyl ether $(3 \times 20 \mathrm{~mL})$, washed over anhydrous magnesium sulfate and evaporated to give a yellow solid of 2.2-dithiosalicylic aldehyde. Flash chromatography ( $4: 1=$ hexane:ethyl acetate) gave $1.70 \mathrm{~g}$ of $2,2^{\prime}$-thiosalicylic aldehyde (oil, $54 \%$ yield) and $0.16 \mathrm{~g}$ of $2.2^{\prime}$ dithiosalicylic aldehyde (white solid, $5 \%$ yield) ${ }^{34-41)}$

\subsection{Electrode modification}

The working electrode used to study laccases was a gold flag $\left(0.4 \mathrm{~cm}^{2}\right)$, which was cleaned with pirana solution $(3: 1$ volumetric ratio of concentrated $\mathrm{H}_{2} \mathrm{SO}_{4}: 30 \% \mathrm{H}_{2} \mathrm{O}_{2}$ ) followed by dilute aqua regia (3:1:5 volumetric ratio of concentrated $\mathrm{HCl}: \mathrm{HNO}_{3}: \mathrm{H}_{2} \mathrm{O}$ ). Laccases were immobilized onto an electrode using the following procedure ${ }^{2)}$ : A clean gold electrode was immersed in the ethyl acetate solution of $10 \mathrm{mM} \mathrm{2,2'-}$ dithiosalicylic aldehyde. The aldehyde-modified electrode was transferred immediately to the solution containing plant laccase $(64 \mu \mathrm{M})$, fungal laccase $(32 \mu \mathrm{M}), \operatorname{LccI}(8 \mu \mathrm{M})$, LccIa $(8 \mu \mathrm{M})$ for 12 hours, respectively (Fig. 1). Between each step, the electrode was washed thoroughly with $0.1 \mathrm{M}$ phosphate buffer ( $\mathrm{pH} \mathrm{6.0)}$.

\subsection{Wild-type Laccase vs. Modified Laccase}

Vectors and strains for cloning and expression

The cDNA than encodes for LccI from Trametes versicolor strain 52J (plasmid pBK117) was obtained from Edgar Ong. The expression vector pPIC3.5K and the strain SMD1 168 (his4, pep4) of Pichia pastoris were purchased from Invitrogen.

2.4.1. Construction of recombinant plasmids and expression of recombinant laccase

The cDNA for laccase from Trametes versicolor was cloned into pPIC3.5K expression vector as an EcoR I- Avr II fragment between the AOX1 inducible promoter and terminator of transcription. PCR was used to amplify lccI in the presence of an upstream primer with EcoR I site and downstream primer that contains Avr $I I$ restriction site. Two DNA polymerase was used according to instructions provided by the manufacturer. The products of PCR were purified from agarose gel, hydrolyzed with EcoR $I$ and $A v r I I$ and ligated
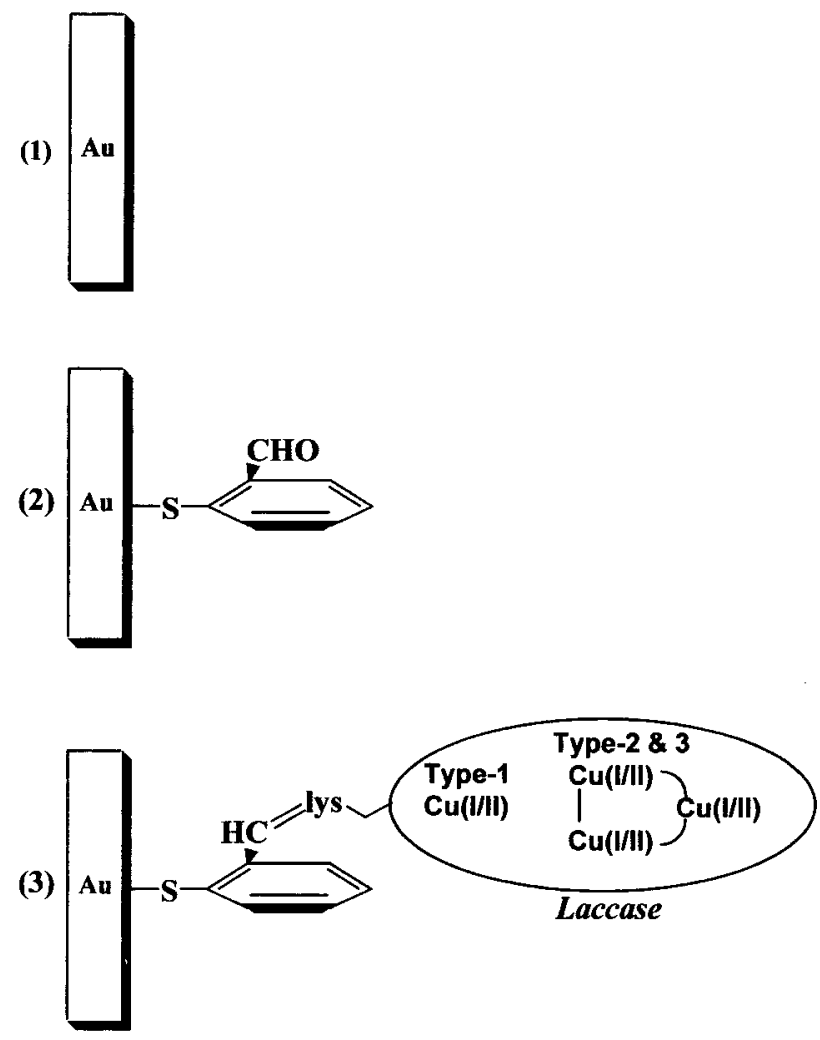

Fig. 1. Schematic diagrams of the immobilizing laccases on the gold electrodes. (1) Preparation of the clean gold flag electrodes $\left(0.4 \mathrm{~cm}^{2}\right)$ rinsed with pirana solution (3:1 volumetric ratio of concentrated $\mathrm{H}_{2} \mathrm{SO}_{4}: 30 \% \mathrm{H}_{2} \mathrm{O}_{2}$ ) followed by dilute aqua regia (3:1:5 volumetric ratio of concentrated $\mathrm{HCl}: \mathrm{HNO}_{3}: \mathrm{H}_{2} \mathrm{O}$ ). (2) Surface immobilization of the 2,2'-dithiosalicylic aldehyde. (3) Binding of laccases, by forming of a Schiff base between one of its surface amines, to the aldehyde.

with pPIC3.5K previously digested with EcoR $I$ and Avr II. The recombinant plasmids pZH98 (pPIC3.5K $+l c c I$ cDNA) and pNP2 (pPIC3.5K+lccl cDNA $\Delta 11+\mathrm{C}$ ) were digested with Sac $I$ and introduced into Pichia pastoris strain SMD1168 by electroporation. Subsequent to transformation, cells were grown on regeneration dextrose medium (RDB) without histidine. After five days, transformants were transferred to methanol medium (MM) supplemented with $0.1 \%$ $\mathrm{Cu}$ and either $0.2 \%$ ABTS and (in pZH98 transformants) or 90\% p-phenylenediamine (in pNP2 transformants). The pZH98 transformants that expressed active LCCI developed a green color due to oxidation of ABTS while the colonies that expressed active LCCla developed a brown color due to polymerization of a phenylendiamine. The most active colonies were cultivated in buffered minimal glycerol medium (BMG, $25 \mathrm{~mL}$ ) until the optical density at $600 \mathrm{~nm}$ was 6-8. The culture was centrifuged and the cell pellet diluted with buffered methanol medium supplemented with $0.1 \mathrm{mM} \mathrm{CuSO}_{4}$ (BMM, $300 \mathrm{~mL}$ ) to an $\mathrm{OD}_{600} \sim 1$. Methanol $(0.5 \%)$ was added daily to induce the expression of laccase.

\subsubsection{Purification of laccase}

Laccases were purified using a BioCAD 700E Perfusion Workstation (PE Biosystems) equipped with a strong anion 
exchange column (Poros $\mathrm{HQ} / \mathrm{M} 4.6 \times 100 \mathrm{~mm}$ ) and the UV detector set at $280 \mathrm{~nm}$. Liquid cultures containing ca. $1 \mathrm{mg} \mathrm{mL}^{-1}$ of total protein were centrifuged at $6000 \mathrm{rpm}$ for 15 minutes at room temperature and the supernatant was concentrated by dialysis against polyethylene glycol (Mw. 15000-20000). The resulting liquid was applied to an $\mathrm{HQ} / \mathrm{M}$ column equilibrated with $20 \mathrm{mM}$ Tris- $\mathrm{HCl}, \mathrm{pH}$. The column was eluted with a $\mathrm{NaCl}$ gradient (0-600 mM in 5 column volumes) dissolved in the same buffer used for column equilibration. The flow rate was $6 \mathrm{~mL} \mathrm{~min} \mathrm{~m}^{-1}$ and $1 \mathrm{~mL}$ fractions were collected. $\mathrm{CuSO}_{4}$ $(0.1 \mathrm{mM})$ was added to the fractions containing purified laccase and left overnight at $4^{\circ} \mathrm{C}$. Fractions were combined and concentrated to yield a concentration of laccase of ca. $5 \mathrm{mg} \mathrm{mL}^{-1}$.

\subsection{Electrochemical measurements}

An EG\&G Potentiostat/Galvanostat, Model 263A was used to obtain cyclic voltammograms of immobilized-laccase. A single-compartment cell was purged with nitrogen gas for ten minutes prior to each measurement. The working electrode was a gold flag $\left(0.4 \mathrm{~cm}^{2}\right)$. The counter and reference electrodes were platinum gauze $\left(4.0 \mathrm{~cm}^{2}\right)$ and saturated calomel electrode (SCE, $0.241 \mathrm{~V}$ vs. NHE), respectively.

\section{Results and Discussion}

\subsection{Redox Potentials: Plant versus Fungal Laccases}

Gold electrodes modified with an aldehyde-terminated thiol monolayer chemically react with amine-containing molecules in the absence of other reagents (Fig. 1). The aldehyde-terminated monolayers with conjugated rings immobilize enzymes onto gold electrodes and facilitate heterogeneous electron transfer between the active site of the bound oxidoreductase and the electrode surface.

Shown in Fig. 2 are cyclic voltammograms (CV) of solu-

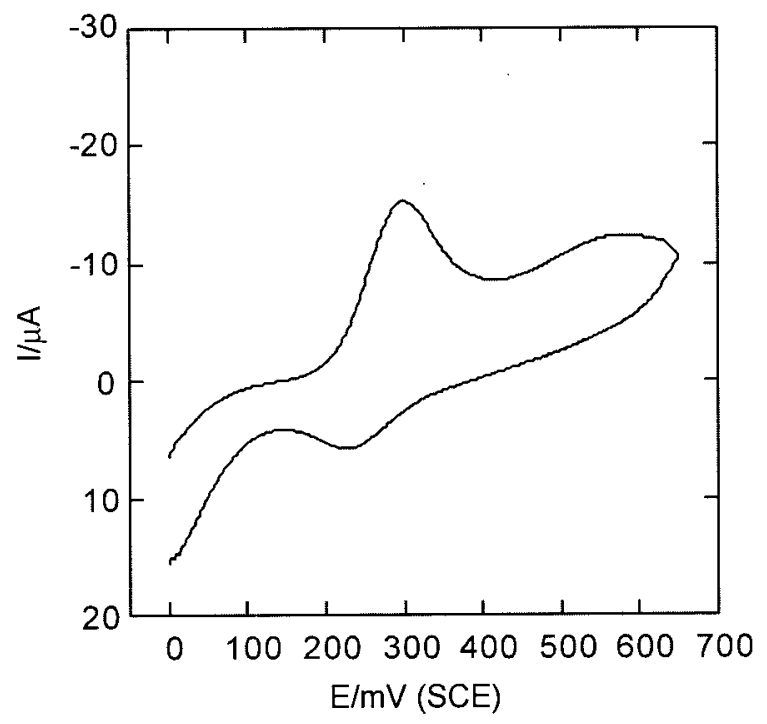

Fig. 2. Cyclic voltammogram of Rhus vernificera plant laccase on the 2,2'-dithiosalicylic aldehyde-modified a gold flag electrode. Scan rate $10 \mathrm{mV} \mathrm{s}^{-1} ; 0.2 \mathrm{M}$ citrate-phosphate buffer ( $\mathrm{pH} 5.85$ ); 25 ${ }^{\circ} \mathrm{C}$ in air. tion containing laccase (Rhus vernificera) on a gold electrode. Plant laccase exhibits a quasi-reversible peak $\left(E_{p, a}-E_{p, c}=70 \mathrm{mV}\right)$ at $\mathrm{pH} 5.85$ with a large anodic wave at $290 \mathrm{mV}$ vs. SCE and a small cathodic wave at $230 \mathrm{mV}$ vs. SCE, respectively. The unbalanced shape of the cyclic voltammogram reflects the successive oxidation of the different copper ions in the active sites with one of these active sites is reversible on the time scale of the experiment. The value of $C_{p, a}: C_{p, c}$ obtained from the charge of the anodic and cathodic peaks is roughly $4: 1$. This result indicates that the number of redox sites oxidized is four times larger than the number of redox sites reduced.

In previous studies, potentiometric and redox titrations of laccase isolated from the Japanese lacquer tree (e.g., Rhus vernicifera) have shown that the reduction potentials of type-1 $\mathrm{Cu}$ (II) and type-3 Cu (II) at $\mathrm{pH} 7.5$ are $193 \mathrm{mV}$ and $242 \mathrm{mV}$ versus NHE, respectively. ${ }^{42)}$ However, the redox potential of plant laccase determined by cyclic voltammetry deviates from that of earlier studies because of differences in $\mathrm{pH}$ and buffer used in the measurement. Cyclic voltammetric studies of plant laccase adsorbed onto the surface of a gold electrode modified with $\beta$-mercaptoproprionate have been reported which exhibit broad anodic peaks at $400 \mathrm{mV}$ versus NHE. ${ }^{43}$ )

In Fig. 3 we compare the cyclic voltammograms of fungal laccase from Pyricularia oryzae after poising the electrode at $0.0 \mathrm{~V}$ versus $\mathrm{SCE}$ and at $0.7 \mathrm{~V}$ versus SCE. The values of $\mathrm{C}_{\mathrm{p}, \mathrm{a}} / \mathrm{C}_{\mathrm{p}, \mathrm{c}}$ obtained from the coulombic areas between the anodic and the cathodic peaks are roughly 1.2 at $0.7 \mathrm{~V}$ versus SCE and 3.5 at $0.0 \mathrm{~V}$ versus SCE, respectively. These results indicate that the oxidation process of the different copper ions in the active site is faster than the reduction process.

The cyclic voltammogram that results when the electrode is poised at a reducing potential $(0.0 \mathrm{~V}$ versus $\mathrm{SCE})$ also indi-

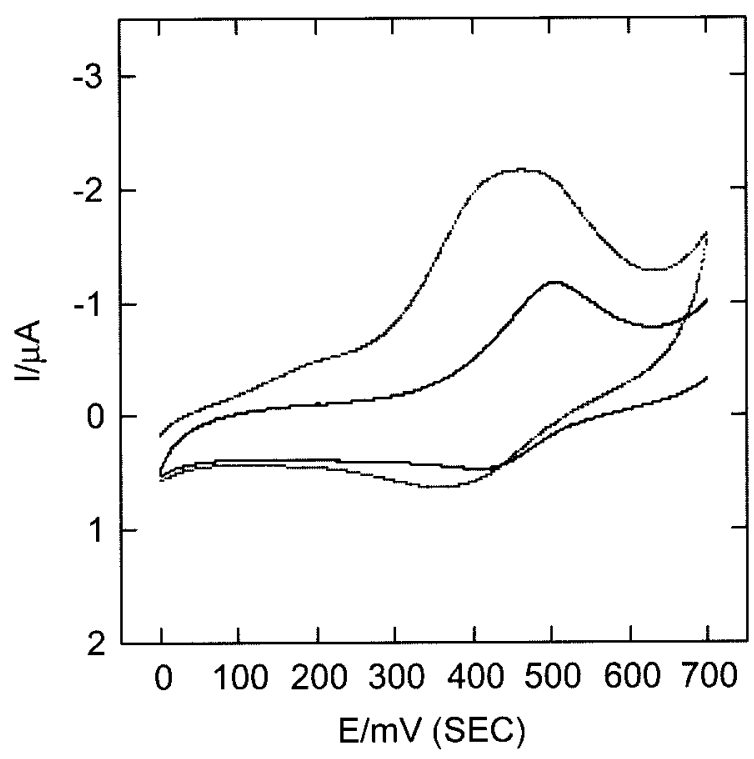

Fig. 3. Cyclic voltammogram of Pyrcularia oryzae fungal laccase on the 2,2'-dithiosalicylic aldehyde-modified a gold flag electrode. Scan rate $2.0 \mathrm{mV} \mathrm{s}^{-1} ; 0.2 \mathrm{M}$ citrate-phosphate buffer ( $\mathrm{pH} \mathrm{5.85),} 25$ ${ }^{\circ} \mathrm{C}$ in air. Measurement conditions: The electrode was poised at 0.0 $\mathrm{V}$ versus SCE (---.) or $0.7 \mathrm{~V}$ versus SCE ( - ) for 30 minutes prior to scanning the potential. 
cates that successive oxidations are less than $100(\alpha n)^{-1} \mathrm{mV}$ apart (individual waves of the oxidation are merged) and at least one of these oxidations is reversible on the time scale of the experiment. However, when the electrode is poised at $0.7 \mathrm{~V}$ versus SCE, the cyclic voltammogram of fungal laccase is quasi-reversible with $E_{1 / 2}$ at $460 \mathrm{mV}$ versus SCE. The ration of the area of the two cathodic waves in the cyclic voltammograms is equivalent.

Furthermore, poising the electrode at an oxidizing potential suggests that it is difficult to transfer electrons from the electrode to the type-2 $\mathrm{Cu}(\mathrm{II} / \mathrm{I})$ and type-3 $\mathrm{Cu}$ (II/I) sites that are further from the surface of laccase than the type-1 $\mathrm{Cu}$. In contrast, poising the electrode at a reducing potential allows enough time for the transfer of electrons from the electrode to the type-2 $\mathrm{Cu}(\mathrm{II} / \mathrm{l})$ and two type-3 Cu (II/).

The higher redox potentials of the copper sites in fungal laccase are in the result of differences in the overall conformation of the protein, a different sequence of amino acids around the type-1 $\mathrm{Cu}$ site. ${ }^{44-47)}$ In other works, direct electrochemistry of fungal laccase isolated from Polyporous versicolor was indistinguishable from the background voltammogram. ${ }^{27,28)}$

\subsection{Measurement of the Redox Potentials: LCCI versus LCCIa}

The two laccases (LCCI and LCCIa) where compared in terms of their relative activity with substrates that have different redox potentials. Results from the electrochemical studies on solutions containing LCCI and LCCIa indicate that the redox potential of the active site of LCCla is shifted to more negative values ( $411 \mathrm{mV}$ vs. NHE) than that found that in other fungal laccases. The solution containing LCCI did not exhibit peaks in the cyclic voltammogram, indicating that the active site in $\mathrm{LCCl}$ is inaccessible electrochemically. However, when LCCIa is immobilized onto an electrode surface, peaks at $0.47 \mathrm{~V}$ versus SCE are visible in the cyclic voltammogram.

When laccasse is immobilized on the modified electrode the rate constant for heterogeneous electron transfer can be determined from the corresponding cyclic voltammograms. The scan rate dependence of the cyclic voltammograms of LCCI is shown in Fig. 4. The cathodic current $\left(i_{p, c}\right)$ in the cyclic voltammogram of LCCI varies linearly with $v$ (scan rat) (Fig. 4 inset) according to equation $1,{ }^{48}$ )

$$
i_{p, c}=\frac{n^{2} F^{2}}{4 R T} v A \Gamma_{o}
$$

where $n$ is the number of electrons transferred, $\mathrm{F}$ is the Faraday constant $\left(9.6484 \times 10^{4} \mathrm{C}_{\text {equiv. }}^{-1}\right), v$ is the scan rate in units of $\mathrm{V} \mathrm{s}^{-1}, \Gamma_{0}$ is the surface concentration of oxidized species $(\mathrm{mol} \mathrm{cm})$, A is the surface area of the electrode $\left(\mathrm{cm}^{2}\right)$.

The value of the rate constant for heterogeneous electron transfer between an electrode and the immobilized laccases can be determined using equation 2 .

$$
k_{s}=m n v F(R T)^{-1}
$$

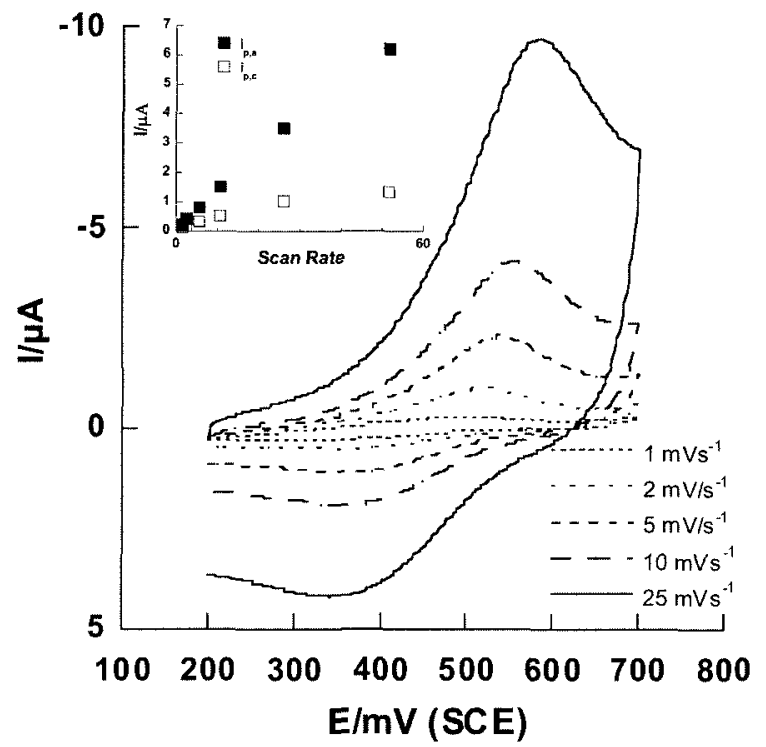

Fig. 4. Cyclic voltammogram of LCCI fungal laccase on the 2,2'dithiosalicylic aldehyde-modified a gold flag electrode as a function of scan rate; $0.2 \mathrm{M}$ citrate-phosphate buffer ( $\mathrm{pH} 5.85$ ), $25^{\circ} \mathrm{C}$. The linear dependence of cathodic and anodic peak currents $\left(i_{p, c}\right.$ and $\left.i_{p . a}\right)$ to scan rate $(v)$ is shown in the inset. Anaerobic conditions were maintained by purging a single-compartment cell with nitrogen gas during the each measurement.

On the basis of Lavirons studies, the value of the kinetic parameter $(m)$ is dependent on $n \times\left(\mathrm{E}_{p, a}-\mathrm{E}_{p, c}\right)$, where $n$ is the number of electrons transferred in the rate determining step, $\mathrm{F}$ is the Faraday constant $\left(9.6484 \times 10^{4} \mathrm{C}_{\text {equiv. }}{ }^{-1}\right), v$ is the scan rate in units of $\mathrm{V} \mathrm{s}^{-1}, \mathrm{R}$ is the gas constant $\left(8.314 \mathrm{JK}^{-}\right.$ ${ }^{1} \mathrm{~mol}^{-1}$ ), and $\mathrm{T}$ is the temperature $(298 \mathrm{~K}){ }^{49)}$ Assuming that $n$ is one, and setting $\alpha=0.5$, the average value of $K_{s}$ is $1.0 \times$ $10^{-2} \mathrm{~s}^{-1}$. For comparison, the rate of heterogeneous electron transfer for MP-11 bound covalently to a cystamine-modified electrode is $12 \mathrm{~s}^{-1} .^{50)}$ The rate of heterogeneous electron transfer for cytochrome $\mathrm{c}$ adsorbed onto a gold electrode modified with 16-mercaptohexadecanoic acid is $0.4 \mathrm{~s}^{-1} .{ }^{51)}$ The rate of heterogeneous electron transfer for the same protein adsorbed onto a monolayer of bipyridinium or anthraquinone components corresponds to 503 and $62 \mathrm{~s}^{-1}$, respectively. ${ }^{52)}$ Results from comparison to other biomolecules which have a heme group on the surface of proteins show that the active site of fungal laccase is not located on the surface of the protein.

In addition, the distorted shape of the cyclic voltammogram of LCCI reflects a case where the separation in potential between successive oxidations is small (i.e., individual waves are merged) and at least one of these oxidations is reversible on the time scale of the experiment. The surface concentration of LCCI was calculated to be $2.0 \times 10^{-11} \mathrm{~mol} \mathrm{~cm}^{-2}{ }^{53)}$ The coverage of laccase is roughly three times greater than a full monolayer of laccase based on a maximum coverage of 6.0 $\times 10^{-12} \mathrm{~mol} / \mathrm{cm}^{-2}$, assuming fungal laccase is spherical in shape with a diameter of $5.5 \times 10^{-9} \mathrm{~cm}$ and is hexagonally close-packed.

Shown in Fig. 5 are cyclic voltammograms of LCCla confined to a gold electrode. The cyclic voltammograms show a 


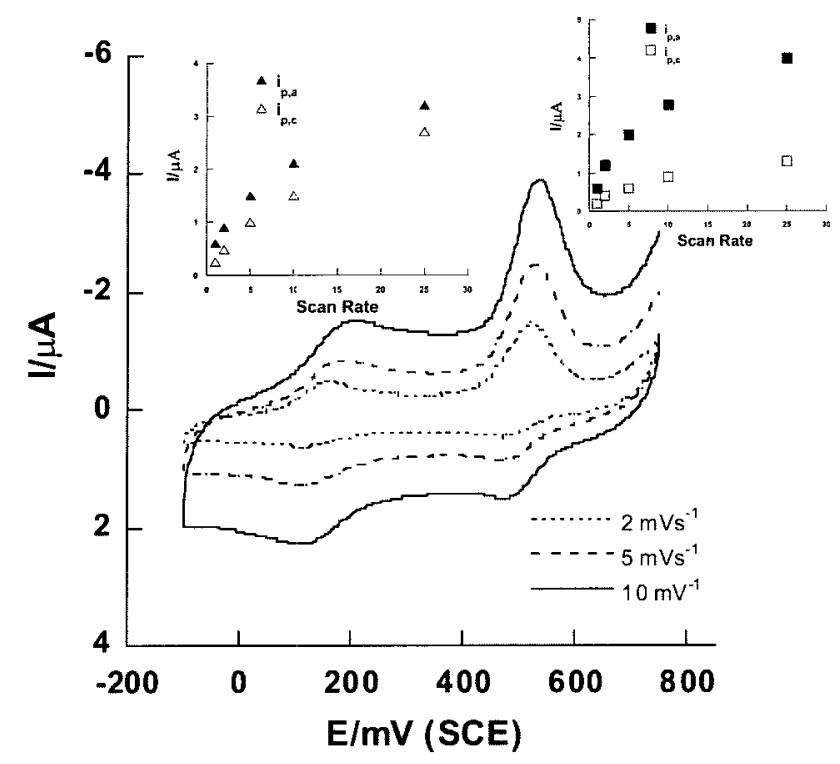

Fig. 5. Cyclic voltammogram of LCCIa fungal laccase on the 2,2'dithiosalicylic aldehyde-modified a gold flag electrode as a function

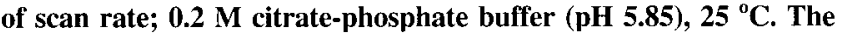
linear dependence of cathodic and anodic peak current to scan rate (v) is shown in the insets. Anaerobic conditions were maintained by purging a single-compartment cell with nitrogen gas during the each measurement.

quasi-reversible wave at $0.18 \mathrm{~V}$ vs. SCE and an irreversible wave at $0.50 \mathrm{~V}$ versus SCE, respectively. This result indicates that reducing the number of amino acid residues at C-terminus of LCCI influences the potential of type-1 copper ion in the active site of laccase but not the redox potential of the type2 and type- 3 copper ions. The distorted shape of the cyclic voltammogram of LCCIa reflects a similar case where the separation in potential between successive oxidations is small (i.e., individual waves are merged) and at least one of these oxidations is reversible on the time scale of the experiment. As with LCCI, the cathodic current $\left(i_{p . c}\right)$ at both $0.15 \mathrm{~V}$ and $0.5 \mathrm{~V}$ versus SCE in the cyclic voltammogram of LCCIa vary linearly with $v$ (scan rate) (Fig. 5 insets). ${ }^{48)}$

The value of the rate constant for electron transfer between an electrode and the immobilized LCCIa can be determined according to equation $2{ }^{49)}$ The average values of $K_{s}$ using the Lavirons method are $1.0 \times 10^{-1} \mathrm{~s}^{-1}$ at $0.18 \mathrm{~V}$ vs. SCE and $4.0 \times 10^{-2} \mathrm{~s}^{-1}$ at $0.50 \mathrm{~V}$ versus SCE. Compared to the rate of heterogeneous electron transfer in LCCI, these results of LCCIa is higher than LCCI. This result supports our previous conclusion, that is, by reducing the number of amino acid residues of $\mathrm{C}$-terminus lowers the barrier to heterogeneous electron transfer. The surface concentration of LCCIa is $2.5 \times$ $10^{-11} \mathrm{~mol} \mathrm{~cm}^{-2}$. 33 )

\section{Conclusions}

There exist in the literature several studies on the electrochemistry of laccases. The significance of our works, as distinguished from previous studies on the bioelectrochemistry of laccase, is that we have developed a method for immobilizing laccase that results in a measurable cyclic voltammogram using a new tether, 2,2'-dithiosalicyclic aldehyde. Also, a new aldehyde-terminated monolayers with conjugated rings immobilize laccases onto gold electrodes and easily facilitate heterogeneous electron transfer between the active site of the bound oxidoreductase and the electrode surface.

Result from these studies indicate that the redox potential of active site of plant laccase from Rhus vernificera is shifted to more negative values ( $255 \mathrm{mV}$ vs. SCE) than that of fungal laccase from Pyricularia oryzae ( $480 \mathrm{mV}$ vs. SCE). Mechanistic studies indicate that the reduction of type-1 $\mathrm{Cu}$ (II/I) precedes the reduction of type- $2 \mathrm{Cu}$ (II/I) and type-3 $\mathrm{Cu}$ (II/ I) when the electrode is poised at different potentials.

The electrochemistry of a wild-type fungal laccase (LCCI) and a truncated fungal laccase (LCCIa) also have been examined using a new tether, 2,2'-dithiosalicyclic aldehyde. A new tether shows that the active sites of both immobilized LCCI and LCCIa are more accessible electrochemically than when LCCI and LCCIa are in solution. A significant consequence of truncating $\mathrm{C}$-terminus of $\mathrm{LCCl}$ is a shift in the redox potential of type- $1 \mathrm{Cu}(\mathrm{II} / \mathrm{I})$ to a more negative value with no effect on the potential of type- $2 \mathrm{Cu}$ (II/I) and type-3 $\mathrm{Cu}$ (II/ I) sites. In Fig. 5, the cyclic voltammograms of LCCIa show that reducing the number of amino acid residues at C-teminus of LCCI via site-directed mutagenesis enhances the rate of heterogeneous electron between an electrode and copper ions in the active site of laccase.

\section{Acknowledgement}

The present research was conducted by the research fund of Dankook University in 2003.

\section{References}

1. E. Katz, D. D. Schlereth, H.-L. Schmidt, and A. J. J. Olsthoorn, J. Electroanal. Chem., 368, 165 (1994).

2. T. Sawaguchi, T. Matsue, and I. Uchida, Bioelectrochem. Bioenerg., 29, 127 (1992).

3. R. C. Horton Jr., T. M. Herne, and D. C. Myles, J. Am. Chem. Soc., 119, 12980 (1997).

4. R. G. Nuzzo, B. R. Zegarski, and L. H. Dubois, J. Am. Chem. Soc., 109, 733 (1987).

5. A. Ulman, J. E. Eilers, and N. Tilman, Langmuir,_5, 1147 (1989).

6. A. Ulman, "An Introduction to Ultrathin Organic Films: From Langmuir-Blogett to Self-Assembly", Academic Press, New York (1991).

7. J. P. Folkers, P. E. Laibinis, and G. M. Whitesides, Langmuir, 8, 1330 (1992).

8. S. E. Creager and G. K. Rowe, J. Electroanal. Chem., 370, 203 (1994).

9. S. E. Creager and K. G. Olsen, Anal. Chim. Acta, 307, 277 (1995).

10. S. E. Creager and G. K. Rowe, J. Electroanal. Chem., 420, 291 (1997).

11. W. R. Everett and I. Fritsch-Faules, Anal. Chim. Acta, 307, 253 (1995).

12. G. Fáhraeus and H. Ljunggren, Biochim. Biophys. Acta, 54, 192 (1961).

13. G. Benfield, S. M. Bocks, K. Bromle' and B. R. Brown, Phytochem., 3, 79 (1964) 
14. B. R. M. Reinhammar and R. Lontie (ed.), "Copper Proteins and Copper Enzymes", Vol. III, CRC Press, Inc., Boca Raton, FL. (1984).

15. U. Takahama, Physiol. Plant., 93, 61 (1995).

16. B. G. Malmström, L.-E. Andreásson, B. Reinhammer and P. D. Boyer (ed.), "The Enzymes", Vol. XIIB Academic Press, New York (1975).

17. B. G. Malmstrom, "Multi-Copper Oxidases", World Scientific, Singapore (1997).

18. R. Malkin and B. G. Malmström, Adv. Enzymol., 33, 177 (1970).

19. L.-E. Andreásson and B. Reinhammar, Biochim. Biophys. Acta, $\mathbf{4 4 5}$, 579 (1976).

20. A. M. Kuznertsov, V. A. Bogdanovskaya, M. R. Tarasevich, and E. F. Gavrilova, FEBS Lett., 215, 219 (1987).

21. M. R. Tarasevich, A. I. Yaropolov, V. A. Bogdanovskaya, and S. D. Varfolomeev, J. Electroanal. Chem., 104, 393 (1979).

22. A. I. Yaropolov, O. V. Skorobogat'ko, S. S. Vartanov, and S. D. Varfolomeev, Appl. Biochem. Biotech., 49, 257 (1994).

23. A. I. Yaropolov, A. N. Kharybin, J. Emnéus, G. Marko-Varga, and L. Gorton, Bioelectrochem. Bioenerg., 40, 49 (1996).

24. J. L. Cole, G. O. Tan, E. K. Yang, K. O. Hodgson, and E. I. Solomon, J. Am. Chem. Soc., 112, 2243 (1990).

25. W. Shin, U. M. Sundaram, J. L. Cole, H. H. Zhang, B. Hedman, K. O. Hodgson, and E. I. Solomon, J. Am. Chem. Soc., 118, 3202 (1996).

26. V. Ducros, A. M. Brzozowski, K. S. Wilson, S. H. Brown, P. tergaard, P. Schneider, D. S. Yaver, P. A. H., and G. J. Davies, Nature Struct. Biol., 5, 310 (1998).

27. C.-W. Lee, H. B. Gray, F. C. Anson, and B. G. Malmström, $J$. Electroanal. Chem., 172, 289 (1984).

28. M. H. Thuesen, O. Farver, B. Reinhammar, and J. Ulstrup, Acta Chem. Scand., 52, 555 (1998).

29. T. Sakurai, O. Ikeda, and S. Suzuki, Inorg. Chem., 29, 4715 (1990)

30. T. Sakurai and F. Nose, Chem. Lett., 1075 (1995).

31. T. Sakurai, Chem. Lett., 481 (1995).

32. T. Sakurai, F. Nose, T. Fujiki, and S. Suzuki, Bull. Chem. Soc. Jpn., 69, 2855 (1996).

33. O. Ikeda and T. Sakurai, Eur. J. Biochem., 219, 813 (1994).

34. G. D. Figuly, C. K. Loop, and J. C. Martin, J. Am. Chem. Soc,, 111,
654 (1989).

35. E. Block, V. Eswarakrishnan, M. Gemon, G. Ofori-Okai, C. Saha, K. Tang, and J. Zubieta, J. Am. Chem. Soc., 111, 658 (1989).

36. K. Smith, C. M. Lindsay, and G. J. Pritchard, J. Am. Chem. Soc., 111, 665 (1989).

37. D. A. Nation, M. R. Taylor, and K. P. Wainwright, J. Chem. Soc., Dalton Trans., 3001 (1996).

38. H. S. Kasmai and S. G. Mischke, Synth. Commu., 763 (1989).

39. P. J. Marini, K. S. Murray, and B. O. West, J. Chem. Soc., Dalton Trans., 143 (1983).

40. D. Leaver, J. Smolicz, and W. H. Stafford, J. Am. Chem. Soc., 740748 (1962).

41. F. D. Toste, A. J. Lough, and W. J. Still, J. Tetrahedron lett., 36, 6619 (1995).

42. B. R. M. Reinhammar, Biochim. Biophys. Acta, 275, 245 (1972).

43. K. H. Hyung, K. Y. Jun, H.-G. Hong, Y. S. Kim, and W. Shin, Bull. Korean Chem. Soc., 18, 564 (1997).

44. E. I. Solomon, T. E. Machonkin, U. M. Sundaram and A. Messerschmidt (ed.), "Multi-Copper Oxidases", World Scientific, River Edge, NJ (1997).

45. J. A. Guckert, M. D. Lowery, and E. I. Solomon, J. Am. Chem. Soc., 117, 2814 (1995).

46. F. Xu, A. E. Palmer, D. S. Yaver, R. M. Berka, G. A. Gambetta, S. H. Brown, and E. I. Solomon, J. Biol. Chem., 274, 12372 (1999).

47. F. Xu, R. M. Berka, J. A. Wahleithner, B. A. Nelson, J. R. Shuster, S. H. Brown, A. E. Palmer, and E. I. Solomon, Biochim. J. 334, 63 (1998).

48. A. J. Bard and L. R. Faulkner, "Electrochemical Methods: Fundamental and Applications", John Wiley \& Sons Inc., NY (1980).

49. E. Laviron, J. Electroanal. Chem., 101, 19 (1979).

50. T. Lötzbeyer, W. Schuhmann, E. Katz, and J. Falter, J. Electroanal. Chem., 377, 291 (1994).

51. S. Song, R. A. Clark, E. F. Bowden, and M. Tarlov, J. Phys. Chem., 97, 6564 (1993).

52. E. Katz and I. Wilner, Langmuir, 13, 3364 (1997).

53. G. K. Rowe, M. T. Carter, J. N. Richardson, and R. W. Murray, Langmuir, 11, 1797 (1995). 